\title{
SOCIAL CHANGE IN CONTEMPORARY NIGERIA: A THEORETICAL DISCOURSE
}

\author{
Solaja Mayowa Oludele \\ Olabisi Onabanjo University, Ago-Iwoye, Nigeria \\ E-mail: solaja.oludele@oouagoiwoye.edu.ng
}

Abstract: This paper examines social change in Nigeria between 1960 and 2015 using the theoretical stance of some classical and contemporary theories of change. Also, the paper focuses on the interpretation of the process of social change in terms of what makes change happen, the characteristics of change and managing change in a given society. The explanatory research design was employed in explaining the socio-cultural, political and economic dimensions of change in Nigeria. The paper concludes that the dynamics and realities of social change in Nigeria could best be explained and understood through a triangulation of change theories with strong empirical roots in sociology.

Key-words: challenges, social change, theory, triangulation, Nigeria

\section{Introduction}

Social change is a challenge for social scientists (Huntington 2003). It is a ubiquitous feature of social reality that widely described and explained the evolution of human societies as well as the transformation in the basic components of human society right from the traditional to modern-day societies (Olagbeju 2015). As a matter of fact, human societies have experienced constant alterations in social values, norms, institutions, relationships and stratification as a result of internal and external forces of social change. The external forces are events that occurred on a large scale, affecting an entire nation or several nations altogether such as climate change. While internal forces are events that occurred on a small scale causing internal structural re-arrangements with far-reaching influences on the social fabric of the society, i.e. demographic change. By virtue of the tenacity of internal and external forces, social change will always attract the attention of sociologists and social-scientific theorists, regardless of its conceptual starting point to address it (University of California Press 2004). This is an undeniable fact even in the current era of the hyper-differentiation of theories- in which many theories are competing for attention and space -not 
that they compete for head-on- with each other as much as they coexist- but because the intellectual arena can, at best, manage very few out of the many theoretical approaches (Turner 2001). However, an examination of the academic literature revealed that the theory of social change is still the weakest branch of sociological theory (Huntington 2003). This is due to the lack of general theory as the basis for understanding the dimensions of change across human societies (Huntington 2003; Turner 2001). Against this backdrop, this paper discussed the dimension of the changes in socio-cultural, political and economic conditions in Nigeria between 1960 and 2015, through a theoretical discourse. The paper also examined the impacts of social change in the social relations and survival of people in contemporary Nigerian societies.

The importance of understanding social change in Nigeria stems largely from the fact that there are unresolved social problems in Nigeria which are occasioned by constant changes in social structure, social relationships and social institutions. And the sociological theories which are supposed to provide a theoretical and practical guide on how to resolve these problems, both in time and space, are puny and unthinkingly applied. Therefore, a study of this nature is significant in many ways in that, it will reveal the strengths and weaknesses of various theories of change and their complementary tendencies in building a robust theoretical solution for the problems confronting sustainable social, economic, political and environmental development in Nigeria.

In addition, this study would assist in improving the understanding of the dynamic nature of social change, its driving forces and inevitability in the current global integration of socio-cultural, economic and political conditions. The study will help social scientists, academicians, politicians and professional development planners to design better policy interventions and socio-political reforms. It would also help the Nigerian government, at all levels, to formulate policies that would enhance the efficacy of managing the internal and external forces of change in order to bring about desirable socioeconomic development for the populace in the contemporary world.

\section{What is Social Change?}

Defining the term 'social change' is highly controversial particularly among sociologists. This is because the object is a social phenomenon, a social process that tends to have diverse dimensions and facets, unfolding at different levels of generality (Morariu and Ignat 2011). However, social change can still be defined as the alteration within the social structure, 
characterized by changes in cultural symbols, rules of behaviour, social organization or value systems (Olagbaju 2015; Morariu and Ignat 2011). Put differently, the social change appears when there is a momentous shakeup in social and cultural elements that form an enduring network of relationships in which interaction between people, organizations, communities, and nations became restructured (Ololube, Dudafa, Uriah, and Agbor 2013). Indeed, social change is either positive or negative in nature. Positive social change connotes desirable development and improvement in the entire or some parts of societal institutions which include culture, economy, education, family, international affairs, law, population, politics and religion, which invariably enhance human and social conditions (Ololube 2011; Ololube, Dudafa, Uriah, and Agbor 2013). While a negative social change depicts dysfunction in the entire or some parts of social structures and institutions which in turn destabilize human and social development.

Consequently, the occurrence of social change in any society (developed or developing) has a significant impact on the social, economic, environmental and political conditions. Socially, social change often alters the social elements (i.e. norms, values, culture, and behaviour patterns) and social arrangements (roles, status, structure and institution). Economically, social change impacts on the process of industrialization, commerce, trade formation, as well as work, human and material administration. Politically, social change influences the political organization and administration of power, resources and governance. Environmentally, social change alters the way natural and mineral resources are being managed and utilized by the people. In essence, social change changes people's behavioural patterns, how they think, and their attitudes of legitimacy and authority. It also alters social structures, economic systems and social values (Giddens and Duneier 2000).

In Nigeria, for example, a lot of modifications have occurred in the social structures (i.e. the shift from three regions to thirty-six states, agriculturebased economy to oil-based economy, military rule to democratic system of government etc.) and cultural patterns (i.e. the gradual shift from the traditional African culture to Western/European culture) over time; some of which have generated series of social problems like bribery and corruption, child labour, family instability, election irregularities, examination malpractices, unemployment, religious conflict, environmental degradation, poverty, insecurity etc. in contemporary Nigerian societies. Meanwhile, the existence of social change in Nigeria has promoted civilization, acculturation, formal education, industrialization, public-private partnerships, globalization as well as technological advancement. Therefore, social change in Nigeria and 
perhaps in other developing countries has brought about positive and negative transformations.

\subsection{Characteristics of Social Change}

Obviously, social change has some characteristics that distinguished them from other forms of social events. An extensive review of the literature showed that there are four main characteristics of social change. These four characteristics are briefly explained with some insights from Nigerian society in order to explain various social, economic and political dynamics of social change in Nigeria between 1960 and 2015. Against this background, the first characteristic that was identified in the literature lies in the belief that social change occurs everywhere naturally- since human society is never static and social, political, economic and cultural changes occur repeatedlynevertheless, the rate of change varies from time to time and place to place. For example, Nigeria and other Third World countries with limited access to up-to-date technology and information communication systems might experience a slow process of change compared to the United States, United Kingdom and other developed countries where there is unlimited access to advanced information communication technology. The second characteristic of social change is the notion that change can be intentional yet often unplanned. For instance, the Structural Adjustment Programme (SAP) which was introduced in the 1980s by the World Bank and IMF as a strategy to recuperate funds from owing countries of the South (developing countries) was a deliberate action, however the way SAP would affect the socioeconomic development of other developing countries was perhaps not envisioned along with the strategy. Hence, social change can have general impacts on entire social institutions, communities, societies or nations.

The third characteristic depicts that social change often generates controversy. For example, the motion from developed countries (United States, Canada and so on) that homosexual rights (i.e. same-sex marriage) should be accepted in Nigeria and other developing countries has caused controversy involving the government, military, religious leaders, and the society at large. In addition, the fourth characteristic posits that some changes matter more than others do. For example, the invention of personal computers was more important than Cabbage Patch dolls. This is because the computer serves many more vital purposes for human development than the latter. 


\subsection{Causes/Agents of Social Change}

The causes of social change across human societies are essentially linked to either internal or external forces; natural or non-natural events; historical or contemporary issues. This perception is supported by the diagram presented below on the factors that can bring about social change in society.

Figure 1: Causes of Social Change

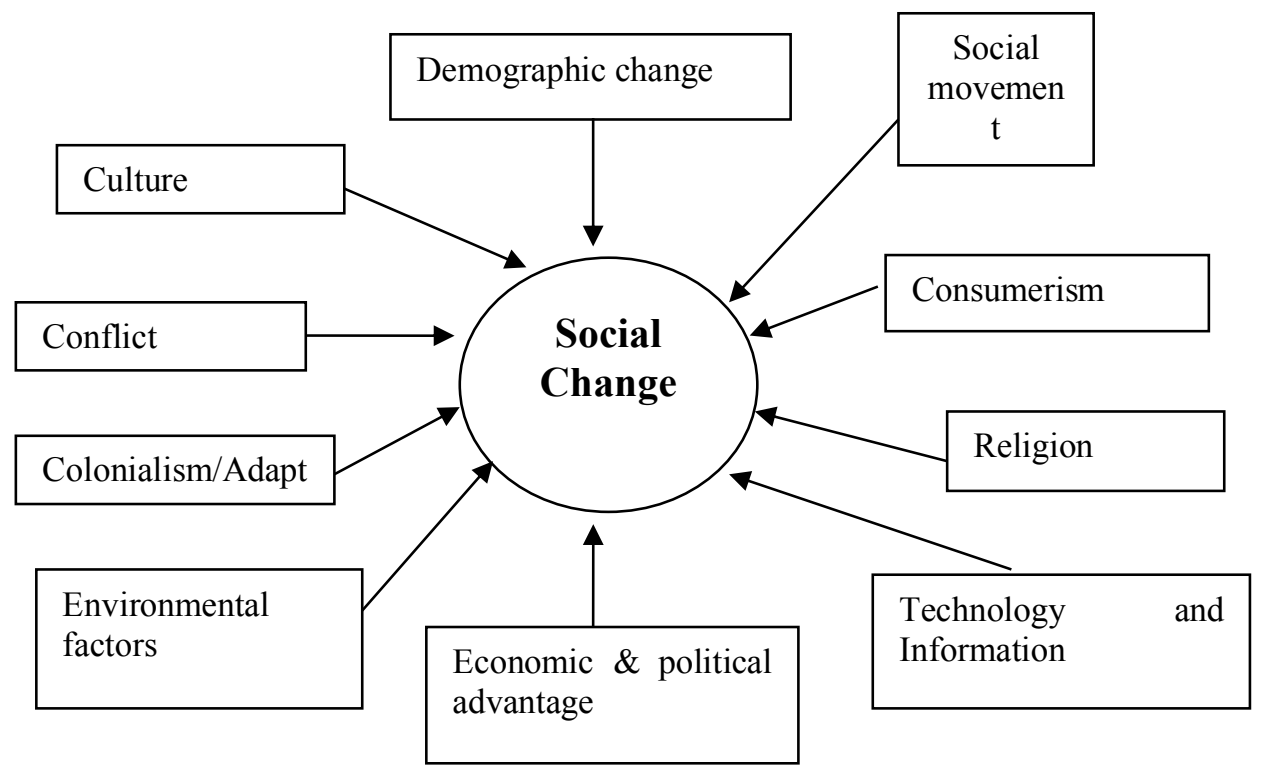

Source: own research

As illustrated above, social change may arise from an alteration in population size, structure and composition (which can arise from migration, mortality or fertility). A change in the population could be unavoidably influenced by the movement of people from rural areas to urban areas, where jobs are easier to find or into previously uninhabited areas where natural resources are plentiful (causing population decrease in rural areas and population increase in urban areas). The city of Lagos is a comical example of this social reality. Population density is Lagos State, Nigeria has engendered the idea of division of labour, speciality and competition among people living in the area. This scenario tallies with the postulation of Durkheim who argued that when the population of a society increases or becomes denser; the only viable way in which the people can survive is through resource/task sharing, specialization and complementarity of roles (Motoi 2017). More so, the losses 
and gains of cultural components are vital proxies of social change. The erosion of Nigeria's cultural values due to colonialism cum neocolonialism, capitalism and its affiliates; democracy, borderless economy and ICT revolution became incompatible with local realities and negatively plunged the country into diverse socio-economic and political crises. This is correct to an extent as argued by Mimiko: For him,

The social fabric was completely devastated and a new culture of violence was implanted. Traditional African systems of conflict resolution were destroyed and, in their places, nothing was given. The democratic process, rudimentary though it was, with great potential as accompanies every human institution, was brutally uprooted and replaced by the authoritarianism of colonialism. A new crop of elites was created, nurtured, and weaned on the altar of violence and colonialism armed with the structures of the modern state to continue to carry out the art and act of subjugation of the mass of the people in the service of colonialism (Mimiko, 2010 cited in Arowolo, 2010).

The above assertion revealed that colonialism serves as a vehicle for the implantation of cultural imperialism in Nigeria. This is also supported by many pieces of evidence to show that colonialism is an imposition of foreign rule over the indigenous traditional political setting and foreign dominance and subjugation of African people in all spheres of their social, political, cultural, economic and religious civilisations (Arowolo 2010). One of the most profound consequences of colonization, as shown by scholars, is the political and economic rape of the colonies which led to what can be regarded as an unbridgeable cultural gap between the nations that were the beneficiaries of colonization and those that were the victims of the colonial assault (Omobowale 2013; Arowolo 2010). The era of colonial pillage and plunder led to the relative stagnation and often precipitous decline of traditional cultural pursuits in the colonies (Arowolo 2010). In the current dispensation, notwithstanding, peoples' cultures have been changed through invention (production of new products, ideas and social patterns), discovery (seeking something that has never been established before, or finding something new in something that already exists) and diffusion (circulation of ideas and objects from one society to another).

Similarly, social tension, social unrest and conflict (between two or more races, religious sects, social classes, political parties, communities etc.) can cause social change. As a result of social unrest or conflict, the general population becomes uneasy, restless and discontented. For example, the Niger-Delta militancy created huge public tension in Nigeria and this forced the federal government into granting amnesty to Niger-Delta militants 
through an amnesty programme. Furthermore, the need for adaptation within social systems may result in social change (Greenwood 2008). For example, the development and adoption of Green Practices in many Nigerian manufacturing companies serve as an adaptive response to climate change. Moreover, another viable source of social change is environmental factors such as earthquake, diseases and climate shifts and other situations produced by people, such as pollution or the overuse of natural resources. Any of these factors could produce a change in the economic base and social ties of a group. For instance, the Food and Agriculture Organization (FAO) reported in 2010, that climate change has pushed approximately 240 million people (i.e. one person out of every four) in sub Saharan Africa (SSA) out of adequate food security and a quality lifestyle into malnourishment, hunger and extreme poverty (Ozor, Umunnakwe and Acheampong 2014). In another dimension though on a lower scale, it is significant to note that the increasing environmental pollution in the Lagos metropolis of Nigeria has forced a majority of the residents, specifically those living in polluted environs, to develop a culture of coping with pollution with concomitant socio-economic implications (Solaja, Omobowale and Alliyu 2015).

Of great significance is the gradual shift in industrialization, social and economic opportunities from the developed countries to the developing countries in recent times. This shift has generated development in bilateral ties between and among countries of the world (such as US-Cuba, US-China, Sino-Africa relations, to mention a few) and a number of multinational corporations in developing countries. For example, China's share of exports from Africa increased from 3\% in 1998 to 15\% in 2008, and it had already outplayed the United States as Africa's largest trading partner since 2009 (Whalley and Weisbrod 2011). Significantly, social change has occurred in Nigeria due to the 'westernization consumerist ideology' that projects the assumption that man's wellbeing is best achieved by amassing extreme wealth (legal or illegal) as quickly as possible, in that African social value and culture are being shaped to the benefit of capitalist system, with emphasis on the idea that economic growth is suitable for the development of human and society. The western ideology has often been used in a normative way to indicate that foreign-made goods are of a high standard, and have better features, with longer life-span than locally made goods. As such, an average Nigerian would prefer to buy everything (new or old) made overseas and refuse to buy anything made in Nigeria. This act has gradually institutionalized a status quo which can be called the Tokunbo phenomenon and the second-hand economy in Nigeria with concomitant socio-economic and environmental implications (Omobowale 2013). Western consumerist 
ideology, therefore, is a particular way of life, considered as superior and advanced identifiable with the West.

Furthermore, social change can occur from people joining together for a common cause. This is called a social movement. Social movements are classified according to the kind of change they seek, which may range from social, religious, political, human rights to economic changes. In Nigeria, the Association for Better Nigeria (ABN) and Safe Nigeria Movement (SNM) stand as pressure groups opposing government policies, plan and agenda at one point or the other. As a matter of fact, social change materialized in response to the contact and interaction between human beings and their material, social and intellectual environment, religion is a vital factor of social change. Religion and society influence each other through the process of secularization. This is partly true because religion deals with beliefs about creation, purpose, destiny, life, and love. Hence, it significantly shapes the behaviour of people (particularly believers). It, therefore, follows, that religion can influence people's attitudes and social ethics, either positively or negatively. For instance, the works of Weber on The Protestant Ethic and The Spirit of Capitalism sufficiently explained the connection between religion and social change only in Europe. Though, much of Weber's works on the role of religion in social transition has been criticized on the ground that one cannot understand Weber's ideology outside the particular social context in which he wrote. Without going too far, the nexus between religion and social change is also apparent in the anti-social and terrorist ideology of the Boko Haram sect in Nigeria aimed at the general acceptance of Sharia law and opposing other man-made laws, of which hundreds of thousands of lives have been lost and property worth millions of naira have been damaged by Boko Haram (Eme and Ibietan 2012). In addition, the growth rate in access to information and communication technologies plays a significant role in improving the quality of decisions to effect social change. To be sure, in the current age of information, non-material and material resources such as information and technology remain critical ingredients in social change (Mutekwe 2012).

\subsection{Major Perspectives on Social Change}

The development of social change theory by classical and contemporary sociologists has been based on two distinct viewpoints which dominate the theoretical circles to date. Some theorists take a change in structure (the establishment of new institutions), composition (inter-group migration) and function (specialization of labour, industrialization, authority relations) as the phenomenon to be explained (Mesure 2009; Chiribuca 2004). While other theorists believe that stability or the re-establishment of some stable state 
(social inequalities) are worthy of examination (Vlasceanu, Miroiu, Paunescu, and Hâncean 2011). These two views were clearly exemplified by Rusu (2008) as the systemic approach and the modern, process-oriented, dynamic - or constructivist- approach. However, the simple truth arising from the two divergent approaches on social change is that it gives the paradigm of social change the feature of Trifunctionality (the theoretical propensity to describe, explain and evaluate social changes).

\subsection{Classical Perspectives on Social Change}

The outstanding works of prominent scholars like Comte, Durkheim, Marx and Weber on social change constitutes the classical viewpoints. The majority of the classical works on social change were published in the nineteenth and early twentieth centuries. Comte's analysis of the evolution of human society marked the beginning of classical studies on social change. According to Comte, human society is a living organism hence, it is dynamic in nature and social change occurs as a result of the constant progress in intellectual or knowledge production. Comte's assumption is largely based on the view that human thoughts, knowledge and intellectual properties are principal factors that drive scientific advancement and other forms of progress that had been transmuting human society from one stage to another. Comte emphasized that since human society is practically a social organism, all the fragments of human society are symbiotic, in the sense that any change that occurs in one of the fragments will facilitate significant changes in the entire social organism and, by extension, propel the movement of human society across the three essential stages of civilization namely; theological (refers to the period when people are yet to discover the natural causes of various phenomena and they attribute them to a supernatural or divine power), metaphysical (refers to the period when people believe that an abstract power or force determines social events) and positive/scientific (refers to the period when people base their explanations about social events on observation, experiment and comparison). Based on the above views, Comte strongly argued that all forms of social change that occur in human societies are engineered by their social progress which can be divided into two categories; progress in scientific knowledge and economic knowledge. In contrast, the notion that social change occurs as a result of social progress had been disputed on the grounds that not every social evolution depicts social advancement.

Furthermore, the work of Emile Durkheim on the division of labour in society advanced another classical perspective to the concept of social change. Durkheim put forward the view that social change emerged from the 
increased division of labour that became necessary as human societies continued to develop from agrarian/mechanical ones to modern/organic ones. In the context of social evolution, as argued by Durkheim, there was a need for human integration as a means to coordinate activities or tasks performed by individuals on the division of labour platform. Furthermore, Durkheim affirmed that it is easy or more convenient to coordinate the interactions of a small group of people (e.g. family) or population that is spread across a particular geographical location with joint dependence on the same resources and modes of operation because they (individuals) are not likely to upset each another, while coordinating the interactions of a large group of people or population is more tedious and only achievable through the division of tasks, specialization and interdependent functions. Consequently, the process of breaking down the whole task into smaller tasks or specialities is usually done in proportion with the size and form of societies as well as the rate at which the population in these societies are growing. This particular view suggests that increased population size might not be the only factor responsible for the division of labour in a given society. Durkheim conceptually explains this viewpoint by submitting that the nearer individuals are to each other, the more their interactions are increasing, diversifying and strengthening, and there is a gradual construction of moral density, better creativity, as well as an improved civilization in the society.

Moreover, other works published by Karl Marx (1818 - 1883) and Max Weber (1864 - 1920) propelled a new direction and perspective to understanding social change. According to them, social change is a product of social conflict which inevitably happened between or among people of different interests and purposes in a given society. This proposition is based on the postulation that people are in a continuing conflict with each other, in the struggle over scarce resources and higher status. For a fact, the three social classification factors that Marx and Weber deeply examined in their works on social change are; the social class (centred on economic differences), the status (based on prestige), and the party (based on political power). Thus, Marx and Weber's perspective to social change is entrenched in the assumption that through social conflict people (especially the marginalized group) are able to rotate access to resources of power, prestige, and material wealth, which invariably do translate to social change and a new social order. An example of the use of conflict by some individuals or a group to engender a change in the social status quo was extensively detailed by Weber (1905) in his popular book entitled Protestant Ethics and the Spirit of Capitalism in which the Protestants went up against the Catholic practices in the early nineteenth century and brought about the progress of 
Protestantism, to the detriment of Catholicism, along with progress in industrialization. Similarly, Marx (1848) in his philosophical expression argued that the ambiguity and alienation between labour and capital, or between the proletariat and the bourgeoisie are the social realities that triggered class struggle or social uprising that often led to social change in the history of human societies. Having examined the classical perspectives on social change, it is also imperative to examine contemporary perspectives on social change.

\subsection{Contemporary Perspectives on Social Change}

The contemporary perspective on social change was pioneered by the dependentist, modernist and post-modernist scholars. Proponents of the contemporary perspective on social change include Parsons (1991), Sorokin (1957), Merton (1949), Dahrendorf (1959), Bourdieu (1972), Giddens (1984), Smelser (1995), Alexander (1998), Habermas (1998), Beck (2000), Bauman (2001), Cohen (2003), and Baudrillard (1992). These scholars variously conceptualized social change from different perspectives, however, the heart of their arguments focused on the dynamics of scientific knowledge, division of labour and culture of the society which is closely connected to the classical point of view.

Realistically, proponents of the contemporary social change theories have exclusive and opposing ideologies from that of the classical scholars as it relates to what could bring about social change and how it can be managed in the modern-day societies. For instance, Parsons (1991) believed that the main causes of social change are differentiation and integration. According to him, differentiation arises in as much as human societies continue to develop, and the existential needs of people begin to increase; society strives to meets the needs by creating new social institutions and joining them with the existing ones so as to function as a system. As a whole system, Parsons further argued that when human societies become more modern, the adaptations among the various social institutions could designate growing distinctions, but the functions they perform remain uninterrupted. Hence, human societies frequently ensure the maintenance or modification of their social institutions regardless of external influences. In the same vein, Smelser (1995) submitted that modifications or alterations in social structure could be expedited through differentiation within and outside the system itself. In the view of Merton (1949), changes within a society occurred due to the failure of the social system to work correctly. This scenario can emerge from several factors, however, he stresses the effect of conflict between cultural goals and 
institutional norms in bringing about internal change in society (Merton, 1949).

Furthermore, Dahrendorf (1959) succinctly opined that social change is a product of the division of classes in capitalist societies. This is based on the assumption that as the division of classes increase, the class situations also become intense. In another point of fact, Alexander (1998) noted that the conflict between classes is not the main cause of social change rather it is the competition and polarization of opinions that arise between classes in capitalist societies. For Bourdieu (1972), social change happens when there is a disconnection or fragmentation between habitus (internalized objective structure, history and practices) and the field that inspires the development of critical consciousness and other causal factors of societal transformation. According to Giddens (1984), the cause of social change is an intrusion into what is often overlooked; which could arise as a result of alterations in external conditions, or attention and consideration on the side of the people that, in turn, lead to a modification in the social structure. In this regard, Habermas (1998) perceives the cause of social change to include population growth, increase in productivity, technological improvements, scientific progress and globalization. For Bauman (2001), the effect of the interaction between the agency and the self-confidence of individuals in contemporary society is the cause of social change. Beck (2000) conceives the unplanned upshot of neoliberal free-market ideals as the factor responsible for social change, while Cohen (2003) opined that social change occurs due to entrepreneurship activities and the creative destruction of the capitalist system and Baudrillard (1992) maintained the opinion that there is no real social change however what exists in contemporary societies is a repetition of history and an impression of change.

\subsection{Synthesizing Classical and Contemporary Theories of Change}

The theoretical tour of social change began with the classical evolutionary theorists. The evolutionary theorists like Auguste Comte, Saint Simon, Frederick Hegel, Herbert Spencer and Emile Durkheim who launched the theorizing exercise of social change by transposing the ideological stance of biological evolution theory (from a simple process to complex processes) propounded by Charles Darwin in 1859 into the social sciences being confident that society and culture experienced changes similar to the laws of biology and organism growth (Mesure 2009; Badescu 2005). The evolutionary proposition presents a linear conception that all societies move from a simple stage to a complex stage of social progress. Since that was the way social changes occurred in the Western world. This assumption simply 
means that every society will inevitably move from a simple to a complex stage, as expressed in Europe. However, it is to be pointed out that evolutionary theory has been seen to suffer some serious drawbacks; mainly the conception of being ethnocentric in the sense that it uses Western societies as the standard of construction. Equally, it has been pointed out that, it is not in all cases that social evolution represents social progress. Also, critics have pointed out that evolutionary models do not tell us why societies like Great Britain have declined from the heights of imperial power or why the ancient civilizations of Egypt, Greece and Rome flourished, declined and ultimately became material for courses in ancient history and classics.

In the effort to explain the rise and fall of human societies, cyclical theorists like Oswald Spengler (1918), Arnold Toynbee (1946), Vilfredo Pareto and Pitirim Sorokin (1948) submitted that social change appears in three stages of a life cycle namely, growth, development and decline. The West is believed to have passed through its maturity in the $18^{\text {th }}$ century and is now moving in the direction of decline. While this proposition is quite convincing as an explanation of history, it says little about any challenge a particular society may expect in response to changes in its environment. However, the revolutionary/radical theorists' like Karl Marx and Ralph Dahrendorf are of the opinion that social change occurs basically by a succession of modes of production, being tense with ambiguities of an economic and social nature (Popescu 2009; Valade 2006; Marx 1964). Conflict theorists were criticized for focusing mainly on the role of social tensions, or dysfunctions of a predominantly economic nature, ignoring the role played by technological progress or external influences in the area of social dynamics such as population, inequalities etc.

The structural-functionalist theorists like Bronislaw Malinowski, Radcliffe-Brown, Talcott Parsons and Robert. K. Merton set to answer some of the criticisms levelled against the conflict theory of change, by submitting that social change occurs as a result of population growth, changes in technology, inequalities among classes and status groups, and efforts by different groups to meet their needs in a world of scarce resources. In this view, there is no prediction of rising and fall or uni-linear social change like it is found in early evolutionary conception or even classical Marxian theory. The main criticism advanced against the functionalist perspective is that it focuses less on social change and conflict. And it was equally criticized for its failure to give adequate account for the sources and causes of social change. However, modernization theorists appeared to give account for sources and cause of social change which functionalists failed to do. 
To modernization theorists, "societies develop in fairly predictable stages through which they become increasingly complex" (Johnson 2007). More emphatically, Walt Whitman Rostow claimed that every society must undergo a sequence of five stages (The traditional society, The preconditions for takeoff, The take-off, The drive to maturity and the age of high mass-consumption) and ascribed the dominant agent of development to technological progress and industrialization (Popescu 2009). The most viable criticism of modernisation theory is the mistake of treating less developed countries (LDCs) as homogeneous (i.e. as having the same characteristics). With this, the theory fails to understand that value systems and institutions tend to be culture-specific. For example, Nigeria and Ghana may be neighbouring countries but their cultures are quite different from one another and may each require different development strategies. Some sociologists, therefore, argued that each LDC needs to be analysed and understood independently. In light of this, it is important to note that all these classical approaches have been the subject of disagreements and have been attacked by many sociologists which drives us to contemporary theories of change.

As part of contemporary theories, dependency theory emerged to attack the modernization theory which held that all societies progress through similar stages of development. Dependency theorists like Walter Rodney, Bauer Prebisch and Andre Gunder Frank believed that developed countries are responsible for impoverishing the less developed countries. Thus, social change occurs due to deteriorating trade terms in the periphery regions which favoured countries belonging to the core regions of the world. As such, dependency theory argued that a marginal number of underdeveloped nations are dependent for their trade and investment on the core of industrialised countries, which maintain the advantages of trade for their own interest (Morariu and Ignat 2011; Giddens 2010). The integration into an increasingly globalised capitalist economy has limited the potential for improvement in the living standards according to the culture of underdeveloped countries (Morariu and Ignat 2011). The dependency theory is criticized for failing to interrogate the applicability of externally imposed development initiatives (Mantuhu 2011). This situation perhaps informed some theorists (especially free-market economists like Bauer and Wolf) to criticize the dependency theory on the basis of corruption, lack of competition, sustainability, and domestic opportunity cost.

In expanding the scope of dependency theory, Immanuel Wallerstein subsequently developed the world-systems theory, premised on the relations between developed countries (core nations) and less developed countries (peripheral nations), shaped by political, economic, historical and 
geographical factors (Morariu and Ignat 2011). Wallerstein argues that in understanding social change the world capitalist economic system should be analysed as a single unit, comprising four overlapping elements:

i. A world market for goods and labour;

ii. The division of the population into capitalists and workers;

iii. An international system of formal and informal political relations among the most powerful countries, whose competition with one another helps shape the world economy;

iv. The carving up of the world into three unequal economic zones (core, periphery and semi-periphery), with wealthier zones exploiting the poorer ones.

The world systems theory was criticized on the grounds that it focused on the economy and not enough on culture, and for being too core-centric and state-centric. Similarly, the positivists criticize the approach as too prone to generalization, lacking quantitative data and failing to put forth a falsifiable proposition. While the orthodox Marxists see the world systems approach as deviating too far from orthodox Marxist principles, in that it does not give enough weight to the concept of social class.

In the same worldview, globalisation theory (a derivative of world systems theory) responds to modernisation theory by seeking to account for presentday development. Globalization theorists stressed the global integration of complex social systems, with a strong emphasis on the economic and cultural transactions as drivers of social change (Capello şi Resmini 2011; Lechner 2009). Baltasiu (2009) and Lechner (2009) argued that global communication and the increased access to information are now transforming the complex social systems which generate visible consequences on the social, economic, political and cultural levels, in every country, creating the premises of the emergence of a global culture and development of a global consciousness. The duo analysed globalisation from two perspectives:

i. Horizontal globalisation, as an external process, dealing with the geographical expansion of the modern world system;

ii. Vertical globalisation, referring to the unification of spaces, determined by the spiritual integration of societies, in other words, the spiritual fulfilment of man.

Furthermore, globalization theory has been criticized for the scepticism of the appealed benefits of globalization (Manfred 2009; Ritzer 2010). Also, antiglobalization theorists' (mostly economists and policymakers) believed that globalization is a process of bringing prosperity to few people and not to the 
majority of people all around the world. Their claim of causation was supported by the success of the Asian tigers as a result of their own policies, and the failure of many of the African states as a result of the opposite policies (Bradhan 2003).

Having reviewed some classical and contemporary theories of change above, it is pertinent to stress that classical theories of change focused on two main perspectives, i.e. social evolution and social revolution which were built on the general assumption that social change was common to all societies, irresistible and it occurred in an undeviating manner (unilinear, multi-linear and universal dimensions) with a fixed life-cycle. However, contemporary change theories see social change as a multi-dimensional phenomenon. Therefore, proponents of contemporary theories of change are of the view that any theory must contain three main elements that should stand in definite relation to one another. The elements are:

1. Structural determinants of social change, such as population changes, the dislocation occasioned by war, or strains and contradictions.

2. Processes and mechanisms of social change, including precipitating mechanisms, social movements, political conflict and accommodation, and entrepreneurial activity.

3. Directions of social change, including structural changes, effects, and consequences.

3. Methodology

The paper employs the use of an explanatory research design in which information is gathered from published articles, journals, newspapers, as well as texts on social change as of 2019. The articles used in this paper were sourced from reputable databases such as Google Scholar, directorate of open access journals (DOAJ) and science direct. Also, the paper focused on the empirical literature that explained the classical and contemporary theories of change; on the one hand, and studies that analysed the forms of sociocultural, political and economic change in Nigeria between 1960 and 2019; on the other hand. The data gathered from the literature is thematically presented in the paper for easy the interpretation of the process of social change in Nigeria.

\section{Theoretical Discussion on Contemporary Nigerian Social Change}

Nigerian social settings can be situated between the two consortiums of social change perspectives (classical and contemporary perspectives). Going by the classical view, it can be said that modern Nigerian society emerged having 
passed through the multi-linear process of social change. By moving from simpler forms based on similar segments (like villages) to more complex forms characterized by specialization and division of labour (Durowade 2002). This is partly true as noted by Olagbaju (2015) and Dike (2008), who reported that Nigeria has experienced a shift from regions to states, from farms to cities, from agriculture to organization, and now political-power shift from the north to the south, however not just by a naturalistic and universalistic foundation, but also by struggle (social movement). This fact tallies with the evolutionary and conflict perspectives that successive stages of change are higher than the preceding stage, i.e. evolution is progressive and non-reversible. The shift from an agriculture-based economy to the organizational-based economy in Nigeria depicts a progressive direction of change from simple to complex, from homogeneity to heterogeneity, from undifferentiated to differentiated, in form and function (Parsons 1991). Yet, functional theorists affirmed that when society becomes more differentiated new institutions are produced yet they must be integrated and incorporated with the other institutions as a part of a whole in order to maintain the equilibrium, stability and social order in society (Parsons 1991).

From a Functionalist perspective, Nigerian society is composed of interdependent components working together to keep up the balance of the whole. Thus, social evolution occurs alongside major changes in social institutions such as political, social, cultural, economic and religious, which further affects the family system, trade formation, value system, dress code, hairstyle, religion and other mundane acts. It also affects everything from education, population, law and administration to the environment and international affairs (Ololube 2011). Unfortunately, all these changes in social institutions are yet to be properly integrated and incorporated in order to ensure desirable socio-economic development and social order. For instance, a majority of Nigerians still practice the culture of pollute-now and clean-up later which continues to create environmental imbalances and socioeconomic challenges in which proactive efforts are now being made to communicate to the coming generation the importance of conserving the depleted natural resources like water, soil, vegetation, wildlife and fisheries.

Coming from the functionalists route, the cyclical theorists, having observed the civilization of Egypt, Greece, Rome and many others affirm that social change has its rise, development and fall, which was demonstrated in the theory of challenge and response- depicting that society that can cope with a changing environment, survive and the one that cannot die. This theory perfectly describes modern Nigerian social evolution where many states still struggle to catch up with a changing business environment due to lack of 
adequate energy, water supply, good roads, health care centres and other social amenities and infrastructure, to bring about a better social structure in the society. In a simple sense, it can be argued that the lack of basic amenities and ineffective government policies to properly integrate the fragmented cultural elements into a whole according to their logical significance will continue to hinder the process of desirable socio-economic development with concomitant implications on human and social improvement.

The greatest implication of this is the upsurge in social problems like corruption, declining quality of education, environmental pollution/degradation, family problems (increased divorce and family abuse/struggle), gender discrimination, governmental abuse of power, limited energy supplies, poverty, racial discrimination, unemployment, and weakening social institutions (Ololube, Dudafa, Uriah, and Agbor 2013). Moreover, cyclical theorists are of the view that every society has a predetermined life cycle of 120 years, i.e. growth, development and decline years (each stage lasting 40 years), and after passing through all these stages of the life cycle returns to the original stage and starts the cycle again.

With this theoretical stance, Nigeria as a country now stands at 58 years, yet it seems to be having certain features across all the three stages of the cyclical theory of change. Nigerian social settings are powered by leaders with limited creative skills, who often see the country's population size (less than 200 million) as a challenge and factor impeding national development even with the huge amount of revenue (money) earned from crude-oil trade and natural resources embedded in the country. The Nigerian government (federal, state and local) continues to maintain the ideology that population size is the cause of the pervasive nature of poverty in Nigeria. In Nigeria, studies have shown that the proportion of people living below a dollar per day stands above a hundred million (Afolayan, Ikwuyatum and Abejide 2008) with a significant number of people losing their children to illness brought about by hunger, lack of shelter, being sick and not being able to see a doctor among other social problems. Meanwhile, some countries like India and China are not as resource-rich as Nigeria with a population that is thrice that of Nigeria, yet they are making remarkable progress in the human and social development process. For example, China continues to be a momentous and dynamic development player in Africa. From 2000 to 2005, China-Africa trade rose from $\$ 10$ billion to $\$ 25$ billion and had reached US $\$ 198.49$ billion by 2012 (Whalley and Weisbrod 2011). Whereas Nigerian governments are fraught with corruption, they are strategically weak in ensuring tax compliance, and the majority of Nigerians are involved in tax avoidance and evasion. This phenomenon portrays the individualistic thinking, serving of 
selfish interests and corruption that exists between the government and the people. In the same context of corruption and contradictions at individual and government levels, the burdensome taxes, dynastic disputes among the ruling elites, the extortionist policy of the various governments and rampant maladministration of government serve as drawbacks and decline forces which may lead the Nigerian society back to where it started years back if care is not taken.

The current Nigerian social settings can also be pictured from a modernization perspective. In the sense that, the recurrent contact between relatively modernised societies and the relatively non-modernised societies acts as a trigger of social change towards a single direction, shaped by the model of the modernised society. Nigerian social structure has been moving from time to time toward foreign and Non-African ways (Olagbaju 2015). The acceptance of a democratic system of government in Nigeria which arose from the need to maintain mutual economic, social and political relationships with the developed countries has brought about the double tragedy of change (social progress and social problems) in modern Nigerian society. The social progress is the notch of enlightenment (which appears in terms of the introduction of democracy, self-freedom, material growth, security etc.). While the social problems are the accompanied social milieu (such as poverty, marginalization, political corruption, cultural devaluation, insurgency, environmental pollution, unemployment, homosexuality, dependency and many other social issues) with varying degrees of consequences for Nigeria's development pursuit (Ololube, Dudafa, Uriah, \& Agbor 2013).

Consequently, dependency and world-system theorists commented that moving Nigerian social structures and culture in the same direction with developed countries will continue to cement Nigeria's dependency on foreign developed countries. The proponents of these theories argued that poverty in low-income countries like Nigeria stems from their manipulation by wealthy countries and multinational corporations based in wealthy countries; in their view "global capitalism locked in a downward spiral of exploitation and poverty" (Giddens 2010). It is also argued that the relations between developed countries (core nations) and less developed countries (peripheral nations) shaped political, economic, historical and geographical factors which do promote exploitation, dependency and poverty in peripheral regions (Wallerstein, 2000). For instance, many wealthy states (United Kingdom, United States, Russia, Germany and recently, Asian Nations.) established factories and companies in Nigeria, using local cheap labour and raw materials in order to minimize production costs and maximize profits with minimal government interference (especially in pollutant industries) and 
repatriate profits to their home country. This, in effect, affected the Nigerian government (federal, state and local) by accumulating profits that are necessary to pursue industrialisation and desirable development. As a result, the Nigerian government is constantly lured to sign or adopt foreign-baked policies and conditionalities (i.e. same-sex marriage, deregulation, subsidies removal, trade liberalization, etc.) in the attempt to borrow from the wealthy ones, thus increasing the country's economic, social and political dependency wherein the need for social change becomes both obvious and inevitable.

Following this view, globalisation theorists are progressively relevant in accounting for social-economic gaps such as gender inequality, level of democracy, and so on, among the countries and regions of the globe. For instance, the acceptance of information communication technology and the integration into the global economic system have continued to put Nigeria under the watch and control of powerful countries of the world (United States, United Kingdom, Russia, France, Germany etc.). This situation has equally put the country in a subordinate position in which social, economic and political institutions can no longer stand or act on their own. Without an iota of doubt, the dimension of social change in Nigeria seems to be following the Neopopulism perspective. Neopopulism perspective has its root in political science. Although the perspective is still relatively young, its popularity is growing, particularly in understanding the dimension of social change in Nigeria. According to the Neopopulists, the rising rate of dependency and exploitation facing developing countries- Nigeria inclusive, will give rise to the redistribution of political power, economic dominance and/or cultural leadership away from what are seen as corrupt, greedy, overcentralized, urban-based oligarchies in favour of empowering, "the common people," particularly those who live in rural or small-town areas (Pantelimon 2015; Payne 2011; Vladimir 2000; di Tella 1965). This fact can simply be inferred from the voting pattern and behaviour of many Nigerians during the April 2015 elections where the call for 'change' overshadowed that of 'power' even though, the recent political change is yet to be felt by the masses.

\section{Conclusion and Summary}

Nigerian society has witnessed a sequential progression from a traditional society to a modern society with a certain level of advancement in the institutions that make up the social system. To be sure, social, political, economic, religious, educational and family institutions have undergone a series of stages of development and change. For example, the Nigerian economy has moved from agriculture-based to crude-oil based which has 
helped to increase the gross domestic product (GDP), purchasing power propensity and national income generation. However, social-economic improvement is yet to be felt by the majority. More so, tertiary education has taken a new dimension from 'free education for all' to 'money education for few' through deregulation policies like privatization and commercialization. The religion practised by Nigerians was formerly traditional religion but it has changed to include Christianity and Islam, and now people with no religion. In addition, the family pattern is getting more nuclear and less extended in Nigeria. This is due to the growing rate of the neo-local mentality among the majority of newly married couples in Nigeria The culture of carrying money around as well as spraying money at occasions has equally changed in the era of the cashless economy. All these evidence-based issues buttress the primary assumption of evolution theories that social change is an inevitable, natural and irreversible phenomenon. Hence, the modern Nigeria social setting is not an exception.

The trend of social change in Nigeria appears in a multi-dimensional pattern deviating from a linear process of change as projected by the majority of classical theorists. This is because the dimensions of social change in Nigerian society cut across different sectors of the economy and society. For instance, the deregulation exercise that took place in the telecommunications sector brought about consequential changes in political administration, healthcare delivery, education, economy, as well as the social condition in Nigeria. However, the social realities of social change in contemporary Nigerian societies have both positive and negative impacts on human and social development. While some sectors of the economy (i.e. communication and technology, education, political participation, financial management, culture diffusion) are experiencing positive improvements (employment opportunities, infrastructural amenities, environmental management, transparency, unity, social and internet security), others are rather witnessing negative changes which cannot be explained in detail by using a linear approach or classical theories alone.

Based on this reality, this paper supported the argument that classical theories of change reflect the dominant thinking of men in a particular sociohistorical setting, most of which are speculative and somewhat subjective when compared with contemporary analysis. True, Durkheim and Sorokin used some empirical indicators but these were exceptions. The others failed to quantify their research by using scientific methodology and empirical data in their studies. Also, the concepts adopted in building classical theories of change can be said to have surplus meanings; they are vague and somewhat ambiguous. Again, some of the classical theorists failed to account for the 
extraneous or intervening variables that come to play in the process of change. This may be due to the fact that proponents of classical theories were social philosophers and not social scientists. Thus, theories as objective, scientific, and positive explanations of human behaviour were not developed. Most were a historical comparison on a broad macro-level of analysis.

However, contemporary theories of change which are based on isolated studies appeared to be foreign-based focusing on global dependence, interrelatedness and exploitation paying little or no attention to indigenous/local forces of social change. Based on this reality, the paper advocates for the application of combined theories (classical and contemporary) of social change which can capture the social dynamics and complexities of Nigerian social settings and give theoretical insights for mapping out the path to true development in Nigeria, Africa and across the world.

\section{References}

Afolayan, Adejumoke, Ikwuyatum, Godwin. and Abejide, Olumuyiwa. 2008. Dynamics of International Migration in Nigeria (A Review Literature). Paper presented as part of the African Perspectives on Human Mobility Programme Funded by Mac Arthur Foundation.

Arowolo, Dare. 2010. "The Effects of Western Civilisation and Culture in Africa." Afro Asian Journal of Social Sciences 1 (1) Quarter IV.

Bachman, Ronet and Schutt, Russell. 2007. The practice of research in criminology and criminal justice (3rd ed.). Thousand Oaks, CA: Sage.

Baltasiu, Radu 2009. The Anthropology of Globalization. Transformations and Attractions (De) code. Publisher Little Wallachia Bucharest.

Badescu, Ionut. 2005. Universal Encyclopedia of Sociology. Vol I. Founders. Publisher Little Wallachia Bucharest.

Bradhan, Pranab 2003. "Crouching Tiger, Lumbering Elephant: A China-India Comparison." In Markets and Governments, edited by Kaushik Basu, Pulin Nayak, and Ranjan Ray. New Delhi: Oxford University Press.

Chiribuca, Dan. 2004. Modernity post-communist transition and reconstruction in Romania. Eikon, Clu-Napoca: Publisher Dacia. 
Capello, Roberta, Rasmini, Laura and Fratesi, Ugo. 2011. Globalisation and Regional Growth in Europe: Past Trends and Future Scenarios. Berlin: SpringerVerlag.

Cohen, David. 2003. Our Modern Times. Massachusetts: The MIT Press.

Dahrendorf, Ralf. 1959. Class and Class Conflict in Industrial Society. California: Stanford University Press.

Di Tella, Torcuato. 1965. "Populism and Reform in Latin America." In Obstacles to Change in Latin America, edited by C. Veliz. Oxford: Oxford University Press.

Dike, Victor. 2008. Leadership, politics, and social change: Nigeria and the struggle for survival.

http://www.africaeconomicanalysis.org/articles/20/1/Leadership-Politicsand-Social-Change-Nigeria-and-the-Struggle-for-Survival/Page1.html. Accessed November 3, 2015.

Dois, Willem. 1996. "Social interaction and cognitive development." In Psychology. Social. Contemporary look, edited by A. Neculau. Iaşi: Polirom.

Durkheim, Emile. 2001. Division of labour. Bucharest: Albatros Publishing House.

Durkheim, Emile. 1884. The Division of Labor in Society. New York: Free Press.

Durowade, Oluwadare. 2002. Social Structure and Social Change in Africa. In The Social Structure of Contemporary African Societies, edited by O. Moses Shoremi, and A. Adewale Oyekunle. Kraft Books Limited, Ibadan, Nigeria.

Eme, Okechukwu Innocent and Ibietan, Jide. 2012. "The Cost of Boko Haram activities in Nigeria." Arabian Journal of Business and Management Review, OMAN Chapter 2 (2):10-23.

Giddens, Anthony. 1984. The Constitution of Society. California: University of California Press.

Giddens, Anthony. 2010. Sociology, translated by O. Gheorghiu. Publisher All Bucharest. 
The government of Romania. 1998. Emergency Ordinance on the deprived areas. Published in the Official Gazette of Romania, Part I, no. 378 of 20 August.

Giddens, Anthony. and Duneier, Mitchell. 2000. Introduction to Sociology (3rd edition). New York and London: W.W. Norton and Company, Inc.

Greenwood, Ronni, Mitchell. 2008. "Intersectional political consciousness: Appreciation for intragroup differences and solidarity in diverse groups." Psychology of Women Quarterly 32: 36-47.

Habermas, Jurgen. 1998. The Postnational Constellation. Massachusetts: The MIT Press.

Huntington, Samuel. 2003. "The Change to Change: Modernization, Development and Politics." Comparative Politics 3 (3): 283-322.

Johnson, Allan. 2007. The Blackwell Dictionary of Sociology. Use the Language Guide Sociology. Bucharest: Humanitas.

Korotayev, Andrey and Zinkina, Julia. 2014. "On the structure of the presentday convergence." Campus-Wide Information Systems 31 (2/3): 139-152.

Lechner, Frank. 2009. Globalization: The Making of World Society. Singapore: Utopia Press.

Manfred, Steger. 2009. Globalization: A Very Short Introduction. Oxford University Press.

Marx, Karl. 1964.Pre-Capitalist Economic Foundations. London: Lawrence and Wishart.

Marx, Karl. 1848. The Communist Manifesto. New York: Signet Classic.

Matunhu, Jephias. 2011. "A Critique of Modernization and Dependency Theories in Africa: Critical Assessment." African Journal of History and Culture 3 (5): 65-72.

Mesure, Simmons. 2009. Auguste Comte. In The history of sociological thought, edited by Gilles Ferreol. Iaşi: Greats European Institute. 
Mimiko, Oluwafemi. 2010. "Would Falola Frustrations Suffice? Tradition, Governance Challenges and the Prospects of Change in Africa." In Toyin Falola: The Man, The Mask, The Muse, edited by Niyi Afolabi. North Carolina: Carolina Academic Press.

Morariu, Corina and Ignat, George. 2011. "Social-Economic Theoretical Connections: Theories of Social Change." Journal of Social Economy 1 (1): 2648.

Mutekwe, Edmore. 2012. "The impact of technology on social change: a sociological perspective." Journal of Research in Peace, Gender and Development 2 (11): 226-238.

Olagbaju, Opeoluwa. 2015. "The Pursuit of Social Change in Nigeria: The Language Education Alternative." Developing Country Studies 5 (9): 63-67.

Ololube, Prince, Dudafa, Johnny, Uriah, Oboada and Agbor, Comfort. 2013. "Education for development; Impediments to the globalization of higher education in Nigeria." International Journal of Educational Foundation and Management 1 (2): 109-130

Ololube, Prince. 2011. Education and society: an interactive approach. Owerri: Springfield Publishers.

Omobowale, Olumuyiwa. 2013. The Tokunbo Phenomenon and the Secondhand Economy in Nigeria. Oxford: Peter Lang.

Ozor, Nicholas., Umunnakwe Polycarp and Acheampong, Ernest. 2014. "Challenges of Food Security in Africa and the Way Forward." Development: the future of global governance. Society for International Development (SID) 56 (3): 404-411.

Pantelimon, Victor. 2015. "Populism and Neo-populism as the Main Characteristics of the XXIst Century Politics." South-East European Journal of Political Science. Gender politics in Post-communist Countries. Vol. III. No. 1.

Parsons, Talcott. 1991. The Social System. London: Routledge.

Payne, Malcolm. 2011. The modern theory of social assistance, translated by Theodora E. D. Ene. Iaşi: Polirom. 
Popescu, Gabriel. 2009. Evoluţia Gândirii Economice, edited by C.H. Beck. Bucharest.

Ritzer, George. 2010. Globalization destroying crops eaten and paradoxes abound. Bucharest: Humanitas.

Rusu, Horatiu. 2008. Social Change and sociocultural identity. European Institute of Iasi.

Solaja, Oludele, Omobowale, Olumuyiwa and Alliyu, Nurudeen. 2015. "The Dimensions of EnvironmentalPollution in Lagos Metropolis, Nigeria." Journal of Sustainable Development in Africa 17 (3): 1-20.

Turner, Jonathan. 2001. "Sociological Theory Today." In Handbook of Sociological Theory, edited by H. J. Turner. Springer: United States.

University of California. 2004. Social Change and Modernity. UC Press E-book collection.

Valade, Bernard. 2006. “Social Change.” In Treaty of Sociology, edited by D. Translation Vasiliu, and A. Ene. Bucharest: Publisher Humanitas.

Vladimir, Tismaneanu. 2000. "Hypotheses on Populism: The Politics of Charismatic Protest." East European Politics and Societies 14 (2): 10.

Vlăsceanu, Lazar, Miroiu, Adrian, Paunescu, Mihai, and Hâncean, MarianGabriel. 2011. Quality of education higher. Quality Barometer 2010. Braşov: Transylvania University Publishing House.

Wallerstein, Immanuel. 2000. The Essential Wallerstein. New York: The New York Press.

Whalley, John and Weisbrod, Aaron. 2011. The contribution of Chinese FDI to Africa's pre-crisis growth Surge. http://www.voxeu.org/article/contribution-chinese-fdi-africa-s-growth. Accessed November 3, 2015. 